\title{
Intellectual development at 10 years in early treated congenital hypothyroidism
}

\author{
W F Simons, P W Fuggle, D B Grant, I Smith
}

\begin{abstract}
Fifty nine children born between 1978 and 1981 with congenital hypothyroidism detected by neonatal screening were assessed at 10 years using the Wechsler intelligence scale for children, together with 59 matched classroom controls. Thirty one children with severe hypothyroidism who had pretreatment plasma thyroxine concentrations of $40 \mathrm{nmol} / \mathrm{l}$ or less had a mean (SD) full scale IQ score of $104 \cdot 7(15 \cdot 1)$, compared with a mean (SD) score of $114.6(16 \cdot 3)$ for the 28 less severely affected children who had pretreatment thyroxine levels greater than $40 \mathrm{nmol}$, and mean (SD) scores of $114.5(12.8)$ and $114.8(13.8)$ respectively for the 31 and 28 control children. In the hypothyroid children the IQ scores at 10 years were closely related to the IQ scores at 5 years and at 3 years. It is concluded that the deficit in IQ score found at 3 and 5 years in children with severe hypothyroidism is still evident at the age of 10 years.

(Arch Dis Child 1994; 71: 232-234)
\end{abstract}

During the last two decades neonatal screening programmes for congenital hypothyroidism have been set up in most countries with advanced health care systems. Although reports on the psychological outcome in children detected by screening indicate an improvement in outcome, with IQ scores generally within the normal range, a number of studies have reported some deficit in intellectual functioning, but this has not always been of statistical significance. ${ }^{1-6}$ In a pilot study in the UK, a group of children with congenital hypothyroidism born between 1978 and 1981 tested at 3 years on the McCarthy general cognitive index showed an overall deficit of four points compared with controls. ${ }^{7}$ When retested at 5 years using the Wechsler preschool and primary scale of intelligence (WPPSI) the group showed a deficit of only two points compared with controls. ${ }^{8}$ At both ages, however, the children with severe hypothyroidism (as judged by low pretreatment plasma thyroxine concentrations) did significantly less well than either the less severe cases or the matched controls.

As yet, relatively few studies $^{9} 10$ have reported follow up beyond about 7 years of age. This paper describes our findings at 10 years using the Wechsler intelligence scale for children - revised (WISC-R) in the group of children with congenital hypothyroidism born between 1978 and 1981, many of whom were previously tested at 3 and 5 years of age.

\section{Subjects and methods \\ SUBJECTS}

Details of the group of children born with congenital hypothyroidism in 1978-81 have already been published, together with the results of psychometric assessments at 1,3 , and 5 years of age. ${ }^{7811}$ Of the original sample of 76 patients, ${ }^{12}$ six have moved abroad and are lost to follow up, one family refused consent for the study, and one child with congenital cataracts could not complete the test procedure. The remaining 68 children were assessed soon after their tenth birthday. Nine of these children, however, have been excluded from the main statistical analysis; three had additional handicaps (two deaf; one Sotos' syndrome) and were at special schools (IQ scores 59, 59, and 73), four did not have matched controls (IQ scores $109,109,120$, and 127), and in two patients no pretreatment thyroxine values were available (IQ scores 97 and 113), leaving a study group of 59 children with congenital hypothyroidism and 59 classroom controls matched for age (within three months), sex, social class, and main language spoken at home. These 59 patients did not differ significantly from the 17 excluded patients with respect to pretreatment thyroxine concentration or age at start of treatment.

As previous studies in this group of children had indicated that more severe hypothyroidism was associated with a greater deficit in IQ score, the subjects have been divided into two groups: 31 children with pretreatment thyroxine concentrations of $40 \mathrm{nmol} / 1$ or less and 28 children with pretreatment thyroxine concentrations greater than $40 \mathrm{nmol} / \mathrm{l}$; the median age at the start of treatment was 26 days (range 10-40 days) in the first group and 27.5 days (range 19-57 days) in the second.

\section{PSYCHOLOGICAL ASSESSMENT}

The children were assessed using the five verbal and five performance subtests of the WISC-R. The tests were carried out in schools by the same psychologist (WFS) who was blind to the results of previous assessments and the pretreatment thyroxine concentrations.

\section{STATISTICAL ANALYSIS}

The statistical significance of differences in mean values between the hypothyroid children and controls, and the two groups of hypothyroid children was assessed using $t$ tests. The full scale IQ results were also compared with the scores obtained at 3 and 5 years using linear regression and correlation analysis. 
Table 1 Mean (SD) values for WISC-R performance, verbal, and full scale scores in 59 children with congenital hypothyroidism and 59 healthy children matched for sex, age, social background (non-manualmanual), and language spoken at home

\begin{tabular}{lll}
\hline & $\begin{array}{l}\text { Children with } \\
\text { congenital hypothyroidism } \\
(n=59)\end{array}$ & $\begin{array}{l}\text { Control } \\
\text { children } \\
(n=59)\end{array}$ \\
\hline Verbal IQ & $109 \cdot 6(16 \cdot 9)$ & $114 \cdot 2(14 \cdot 0)$ \\
Performance IQ & $107 \cdot 4(15 \cdot 1)$ & $112 \cdot 3(11 \cdot 7)$ \\
Full scale IQ & $109 \cdot 4(16 \cdot 3)$ & $114 \cdot 6(13 \cdot 2)$ \\
\hline
\end{tabular}

A probability of less than 0.05 was taken to indicate statistical significance.

\section{Results}

Table 1 gives the mean verbal, performance, and full scale IQ scores for all the hypothyroid children and their controls. Overall, the mean scores for the hypothyroid children were four to five points below those for the controls, but the differences were not statistically significant.

Table 2 gives the mean results for all the WISC-R subtests together with the verbal, performance, and full scale scores for the hypothyroid children divided into two groups by pretreatment thyroxine, and for their controls. The children with severe congenital hypothyroidism (pretreatment thyroxine 40 $\mathrm{nmol} / \mathrm{l}$ or less) showed a deficit of about $10 \mathrm{IQ}$ points with respect to the verbal, performance, and full scale scores, compared with those with less severe congenital hypothyroidism (pretreatment thyroxine greater then $40 \mathrm{nmol} / \mathrm{l}$ ) and to the two groups of controls. This deficit in the children with more severe hypothyroidism was present across all the subtests except for picture completion.

Table 3 gives the mean results for the full scale IQ scores for the two groups of children with congenital hypothyroidism, compared with the mean full scale scores previously obtained at 3 and 5 years. At all three ages the differences between the scores for the children with severe congenital hypothyroidism and those less severely affected reach statistical significance $(t 2.06-2.93 ; \mathrm{p}<0.05$ to $<0.01)$.

IQ assessments at 10 years showed highly significant correlations with the results obtained at 3 years $(n=48 ; r=0.73 ; p<0.0001)$

Table 2 Mean (SD) values for the WISC-R subtest scores and the composite performance, verbal, and full scale scores in 31 children with severe hypothyroidism (pretreatment thyroxine $40 \mathrm{nmol}$ or less) and 28 children with less severe hypothyroidism (pretreatment thyroxine greater than $40 \mathrm{nmol} /$ ), together with the mean scores for their respective controls

\begin{tabular}{|c|c|c|c|c|}
\hline & \multicolumn{2}{|c|}{$\begin{array}{l}\text { Pretreatment } \\
\text { thyroxine } \leqslant 40 \text { nmoll } \\
(n=31)\end{array}$} & \multicolumn{2}{|c|}{$\begin{array}{l}\text { Pretreatment } \\
\text { thyroxine }>40 \mathrm{nmoll} \\
(n=28)\end{array}$} \\
\hline & Patients & Controls & Patients & Controls \\
\hline $\begin{array}{l}\text { WISC-R subtest } \\
\text { Information } \\
\text { Similarities } \\
\text { Arithmetic } \\
\text { Vocabulary } \\
\text { Comprehension } \\
\text { Picture completion } \\
\text { Picture arrangement } \\
\text { Block design } \\
\text { Object assembly } \\
\text { Coding } \\
\text { Verbal IQ } \\
\text { Performance IQ } \\
\text { Full scale IQ }\end{array}$ & 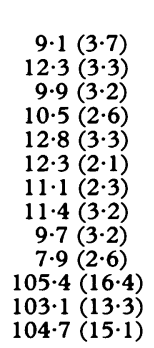 & $\begin{array}{r}9 \cdot 8(2 \cdot 7) \\
13.5(2.9) \\
11.9(2 \cdot 8) \\
11.2(2.1) \\
14.2(2.9) \\
12.4(2.4) \\
12.3(2.9) \\
12.3(2 \cdot 7) \\
11.4(2.6) \\
11.3(2.4) \\
112.8(13.0) \\
113.4(11.6) \\
114.5(12.8)\end{array}$ & $\begin{array}{c}10.3(3.2) \\
14.0(3.0) \\
11.7(3.6) \\
11.8(2.8) \\
13.9(2.8) \\
12.1(2.5) \\
12.4(2.9) \\
12.4(3.8) \\
11.1(3.5) \\
10.8(3.3) \\
114.2(16.5) \\
112.0(15.8) \\
114.6(16.3)\end{array}$ & $\begin{array}{l}10.4(3.1) \\
14.3(2.6) \\
11.7(3.5) \\
11.7(2.1) \\
14.7(2.6) \\
12.0(1.4) \\
11.3(3.0) \\
11.9(2.5) \\
10.7(2.5) \\
12.0(3.2) \\
115.7(15.2) \\
111.0(11.9) \\
114.8(13.8)\end{array}$ \\
\hline
\end{tabular}

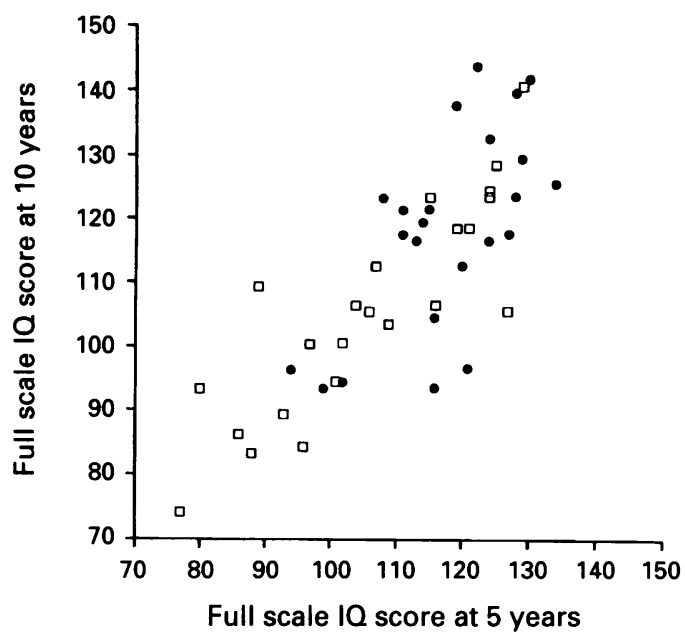

Full scale WISC-R IQ scores at 10 years versus full scale WPSSI scores at 5 years in 46 children with congenital hypothyroidism diagnosed by screening. Open squares represent patients with pretreatment thyroxine

concentrations of $\leqslant 40$ nmoll; closed circles represent patients with pretreatment thyroxine concentrations $>40$ nmoll $(\mathrm{r}=0.78)$.

and at 5 years $(\mathrm{n}=46 ; r=0.78 ; \mathrm{p}<0.0001)$. The figure shows a plot of IQ scores at 10 years against results obtained at 5 years for the same 46 children.

\section{Discussion}

The results of this study show clearly that although the mean IQ scores in children with early treated congenital hypothyroidism generally fall within two standard deviations of the mean for the control population, deficits in IQ scores are consistently present in those children who have more severe forms of hypothyroidism (plasma thyroxine $40 \mathrm{nmol} / 1$ or less at diagnosis). This is evident by 3 years of age and persists at 5 and 10 years, and is not compensated for by five years of full time education.

These results are in agreement with the findings in a national cohort of children born between 1982 and 1984 (after the children in the present study) and tested at the age of 5 years. The results showed a non-linear association between pretreatment thyroxine and later intellectual functioning, with a threshold effect at about $43 \mathrm{nmol} / 1 .{ }^{3}$ Owing to the smaller sample size in the present study, however, the

Table 3 Mean (SD) values for WISC-R full scale scores at 10 years in children with severe hypothyroidism (pretreatment thyroxine $40 \mathrm{nmol} / \mathrm{l}$ or less) and less severe hypothyroidism (pretreatment thyroxine greater than 40 nmoll), together with results previously obtained for the mean full scale WPPSI scores at 5 years and McCarthy (short form) scores at 3 years

\begin{tabular}{|c|c|c|}
\hline & \multicolumn{2}{|c|}{ Pretreatment thyroxine concentration } \\
\hline & $\leqslant 40 \mathrm{nmoll}$ & $>40 \mathrm{nmoll}$ \\
\hline \multicolumn{3}{|c|}{ WISC-R: results at 10 years } \\
\hline No of children tested & 31 & 28 \\
\hline $\begin{array}{l}\text { Mean full scale score } \\
\text { WPPSI. }\end{array}$ & $104 \cdot 7(15 \cdot 1)$ & $114 \cdot 6(16 \cdot 3)^{\star}$ \\
\hline \multicolumn{3}{|l|}{ WPPSI: results at 5 years } \\
\hline No of children tested & 22 & 24 \\
\hline Mean full scale score & $104 \cdot 8(15 \cdot 3)$ & $116 \cdot 0(10 \cdot 5) \dagger$ \\
\hline \multicolumn{3}{|c|}{ McCarthy scales (short form): results at 3 years } \\
\hline No of children tested & 26 & 22 \\
\hline Mean full scale score & $96 \cdot 8(11 \cdot 6)$ & $108 \cdot 5(17 \cdot 1) \dagger$ \\
\hline
\end{tabular}

${ }^{\star} \mathrm{p}<0.05 ; \mathrm{tp}<0.01$. 
data have not been subjected to the same statistical analysis with regard to non-linearity as in the national study. Nevertheless, the present data are entirely consistent with the findings in the larger study.

Most published studies of children with congenital hypothyroidism detected by screening which have examined intellectual development have observed some evidence of intellectual impairment despite early treatment. Small, non-significant IQ deficits compared with controls have been reported in Quebec (four point deficit at 5 years), ${ }^{1}$ Switzerland (four point deficit at 4 years), ${ }^{2}$ Toronto (four point IQ deficit at 5 years), ${ }^{3}$ and France (two point IQ deficit at four years). ${ }^{5}$ Larger statistically significant deficits have been reported in Norway (11 point IQ deficit at 6 years) ${ }^{6}$ and Australia (15 point verbal IQ deficit and six point performance IQ deficit at 5 years) ${ }^{4}$ Some studies have also suggested an association with the severity of the disorder at diagnosis; for example, the Toronto study found a 12 point deficit between severely affected children and those less severely affected. ${ }^{3}$

The New England Congenital Hypothyroidism Collaborative study is an important exception, finding no intellectual impairment at any age. ${ }^{9}$ Of 72 patients reported at 9 years of age there was a non-significant deficit of three IQ points, with no evidence of academic impairment compared with non-affected peers. No relation between severity of hypothyroidism and outcome was apparent. Differences in the proportion of patients with pretreatment thyroxine concentrations less than the $\mathbf{4 0} \mathrm{nmol} / \mathrm{l}$ threshold might explain the differences between these studies.

These results also show that assessments carried out at 3 and 5 years of age are highly predictive of intellectual functioning at 10 years in children with congenital hypothyroidism. This finding would be expected in normal children and supports the view that the speed of intellectual development in children with congenital hypothyroidism does not significantly deviate from the expected pattern during the years of primary education.

In conclusion, our findings indicate that at 10 years there is a persistent impairment of IQ score in children with severe congenital hypothyroidism, despite early treatment, and it remains to be seen whether this is associated with educational or behavioural difficulties.

We thank all the paediatricians who have helped with this study, and also the families who agreed to participate. The work was supported by a project grant from the Medical Research Supported.

1 Glorieux J, Dussault JH, Morisette J, et al. Follow up at ages 5 and 7 years on mental development in children with hypothyroidism detected by Quebec screening program. hypothyroidism detected by

2 Illig R, Largeo RH, Weber M, et al. Sixty children with congenital hypothyroidism detected by neonatal screening: mental development at 1,4 , and 7 years: a longitudinal mental development at 1, 4, and 7 years: a longitud
study. Acta Endocrinol 1986; 279 (suppl): 346-53.

3 Rovet J, Ehrlich R, Sorboda D. Intellectual outcome in children with fetal hypothyroidism. $\mathcal{f}$ Pediatr $1987 ; 110$ 700-4.

4 Rickards A, Coakley J, Francis I, Armstrong S, Medson H, Connelly J. Results of follow-up at five years in a group of hypothyroid Australian children detected by newborm screening In: Delange F, Fisher DA, Glinoer Research in congenital hypothyroidism. London: Plenum Press, 1989: 341.

5 Toublanc JE, Rives S, Acosta A, Chicaud J. Le développement psychomoteur et intellectuel chez 52 enfants atteints d'hypothyoìdie congénitale dépistée à la naissance. Arch Fr Pediatr 1990; 47: 191-5.

6 Heyerdahl S, Kase BF, Lie SO. Intellectual development in children with congenital hypothyroidism in relation to recommended thyroxine treatment. $f$ Pediatr $1991 ; 118$ 850-7.

7 Murphy G, Hulse JA, Jackson D, et al. Early treated hypothyroidism: development at three years. Arch Dis Child 1986; 61: 671-5.

8 Fuggle PW, Grant DB, Sith I, Murphy G. Intelligence, motor skills and behaviour at five years in early-treated motor skills and behaviour at five years in early-treated congenital $570-4$.

9 New England Congenital Hypothyroidism Collaborative. Elementary school performance of children with congenital hypothyroidism. $\mathcal{F}$ Pediatr 1990; 116: 27-32.

10 Glorieux J, Dussault J, Van Vliet G. Intellectual development at age 12 years of children with congenital hypothyroidism diagnosed by neonatal screening. $₹$ Pediat 1992; 121: $581-4$

11 Hulse JA, Grant DB, Jackson D, Clayton BE. Growth, development and reassessment of hypothyroid infants development and reassessment of hypothyroid
diagnosed by screening. $B M \mathcal{\Im} 1982 ; 284: 1435-7$.

12 Hulse JA, Grant DB, Clayton BE, et al. Population screening for congenital hypothyroidism. BMF 1980; 280: ing for

13 Tillotson SL, Fuggle PW, Smith I, Ades AE, Grant DB. The relation between biochemical severity and intelligence in early treated congenital hypothyroidism: threshold effect. $B M \mathcal{Y}$ (in press). 